\title{
ENSAIO PARA UMA ANÁLISE DOS PRECEDENTES JUDICIAIS NOS CONFLITOS SOCIOAMBIENTAIS, FRENTE À TEORIA DO ESTADO E DA CONSTITUIÇÃO
}

\author{
AN ARTICLE FOR AN ANALYSES OF \\ PRECEDENTS IN THE SCOPE OF \\ SOCIO-ENVIRONMENTAL DISPUTES, \\ IN LIGHT OF THE THEORY OF THE \\ STATE AND THE CONSTITUTION
}

\section{Rudson Marcos ${ }^{1}$}

RESUMO: $O$ presente artigo trata da tentativa de aproximação entre os Precedentes Judiciais, voltados, especialmente, para a aplicação em Conflitos Socioambientais, com o modelo de Estado que possa dar respostas satisfatórias para a Sociedade brasileira, no presente estágio civilizacional. $\mathrm{O}$ trabalho foca, principalmente, o momento social contemporâneo, consubstanciadona Sociedade de Risco, vivenciado sob o paradigma do esgotamento dos recursos naturais em seu modo de produção, típico da era industrial. O objetivo principal desta reflexão é fomentar um projeto cultural baseado na valorização da sustentabilidade, em suas dimensões ambientais, econômicas e, principalmente, na dimensão social. Posterior- mente à delimitação sintética dos campos disciplinares aplicáveis, a presente investigação destaca a importância dos Precedentes Judiciais na resolução dos Conflitos Socioambientais, como tentativa de efetivação de mecanismo processualmente adequado a respostas emergentes que a Sociedade almeja dos Poderes Constituídos do Estado, em especial do Poder Judiciário.

PALAVRAS-CHAVE: Precedentes judiciais. Conflitos socioambientais. Teoria do Estado e da Constituição.

ABSTRACT: The article presents a research about the attempt of approximation among Precedents that are in favor of, especially, the application in socio-environmental disputes, under a

1 Juiz de Direito, em Florianópolis/SC .Diretor de ensino e professor de Direito Processual Civil da Escola Superior da Magistratura do Estado de Santa Catarina (Esmesc). Doutorando em Ciência Jurídica pela Universidade do Vale do Itajaí (Univali), em regime de dupla titulação com a Universidad de Alicante - UA/Espanha. Mestre em Ciência Jurídica pela Univali. Especialista em Direito Processual Civil pelo Complexo de Ensino Superior de Santa Cataria (Cesusc). Graduado em Direito pela Univali. E-mail: rudsontjsc@gmail.com 
model of State that is to give satisfactory answers to Brazilian society, in our current stage. The work has focused on, mainly, the contemporary social movement, based on a Society of Risks, set under the paradigm of lack of natural resources in its usual way of production, typical of the industrial era. The main objective of this scrutiny is to give birth to a cultural project based on the valorization of sustainability, in its environmental and economical spheres, and mainly in its social sphere. Subsequently to the synthetic delimitation of the applicable disciplinary fields, the scrutiny highlights the importance of Precedents in social-environmental conflict resolution, as an attempt for the effectiveness of a procedural mechanism that is adequate to the emerging replies that society has claimed against the powers of the State, especially the judiciary.

KEY WORDS: Precedent. Socio-environmental disputes. Theory of State and the Constitution.

\section{INTRODUÇÃO}

Este artigo apresenta reflexão inicial sobre a potencialidade dos Precedentes Judiciais, como mecanismo processual apto a conceber respostas adequadas e urgentes, almejadas pela Sociedade brasileira, especialmente diante das prementes questões relacionadas aos conflitos socioambientais.

O presente ensaio está dividido em três partes. A primeira parte está destinada a apresentar, brevemente, Teorias que embasam a existência do Estado, bem como o modelo teórico Constitucional que impulsiona o Estado brasileiro.

A segunda parte deste artigo dedica-se à análise dos Precedentes Judiciais, como modalidade técnica de aplicação do Direito, os quais guardam consonância com os anseios, cada vez mais crescentes, da Sociedade brasileira e, de outro lado, mostra-se como ferramenta em que o Estado nacional tem dotando o sistema jurídico pátrio, paulatinamente.

A terceira seção deste ensaio pretende alinhar algumas contribuições teóricas e práticas sobre a utilização da técnica dos Precedentes Judiciais, na resolução de Conflitos Socioambientais, com viés a propiciar uma melhor adequação quanto ao fator tempo, consistente na velocidade da resposta às demandas submetidas ao Estado com a urgência na proteção do patrimô- 
nio ecologicamente equilibrado, almejado pela Sociedade.

Quanto à metodologia empregada, tem-se que na fase de investigação foi utilizado o método indutivo; na fase de tratamento de dados, o método cartesiano e no presente relatório, aplica-se o método lógico-dedutivo. Salienta-se que ao longo da pesquisa foram utilizadas as técnicas do referente, da categoria, do conceito operacional e da pesquisa bibliográfica ${ }^{2}$.

\section{TEORIA DO ESTADO E DA CONSTITUIÇÃO}

De maneira geral, a função do Estado está vinculada à ideia de instrumentalidade, no sentido de cooperação de indivíduos em um determinado âmbito territorial e social, instituída a partir da necessidade do homem de estabelecer um modo comum de viver, objetivando a harmonização de todas as oposições existentes dentro de uma determinada área geopolítica.

Essa concepção de função do Estado é difundida por Heller, para quem:

A função do Estado consiste, pois, na organização e ativação autônomas da cooperação social-territorial, fundada na necessidade histórica de um status vivendi comum que harmonize todas as oposições de interesses dentro de uma zona geográfica, a qual, enquanto não exista um Estado mundial, aparece delimitada por outros grupos territoriais de dominação de natureza semelhante. (HELLER, 1968, p. 245).

Esta concepção instrumental do Estado refere-se ao Homem, em si considerado, como o fim último estatal, devendo este pautar suas ações concretas e políticas governamentais sempre na busca do Bem Comum.

Neste sentido, tem-se a caracterização da função do Estado Contemporâneo, proposta por Pasold, para quem:

2 A metodologia aplicada no presente trabalho tem como base a seguinte obra: PASOLD, Cesar Luiz. Metodologia da pesquisa jurídica: teoria e prática. 13. ed. rev. atual. ampl. Florianópolis: Conceito Editorial, 2015. 
Entre as características propostas para o Estado Contemporâneo, insisto na sua condição instrumental e no seu compromisso com o Bem Comum, compreendendo este, além da satisfação das necessidades materiais, a dimensão do respeito aos Valores Fundamentais da Pessoa Humana, que devem sustentar o Interesse Comum. (PASOLD, 2013, p. 49).

E arremata:

A realidade contemporânea, sem dúvida, requer do Estado não somente uma eficiência administrativa, mas e principalmente uma atuação - legítima e dinâmica - voltada à participação consciente do Homem na consecução de seu nobre destino. Isto será feito através da dinâmica social que implica a utilização do instrumento estatal em favor da criação e da realização de condições de sensibilidade, racionalidade e acessibilidade - com Igualdade de possibilidades - para o Homem, frente a alternativas efetivamente existentes nos planos políticos, social, cultural e econômico. (PASOLD, 2013, p. 50).

É nessa mesma perspectiva instrumental do Estado que se desenvolve a Teoria do Constitucionalismo, voltado para a consecução dos projetos políticos, econômicos e, principalmente, os sociais almejados pela Sociedade que compõe o tecido Estatal.

O fortalecimento de um projeto cultural que inclui o Constitucionalismo como instrumento de realização das aspirações do Homem, como o ser que desfruta de posição central na Teoria do Estado é de suma importância para o fortalecimento, embasamento e consolidação das projeções futuras de progresso estatal.

Pelo imperativo Kantiano o Homem deve ser considerado como um fim em si mesmo, não devendo se conceber a utilização de políticas e ações governamentais que reduzem a dignidade do Homem, "coisificando-o", para o fim de atendimento de interesses de outrem.

Nesse panorama, desenvolve-se o Constitucionalismo como importante instrumento jurídico para a compreensão da configuração do Estado. Sob a perspectiva de desenvolvimento concre- 
to do Constitucionalismo, não só plano nacional como também na esfera transnacional, Morais e Nascimento defendem que:

O Direito, e especialmente o Direito Constitucional, como área social que é, exige continuamente uma inter-ação entre o povo e a Carta Maior do país, que serve de fundamento às demais normas e legitima os poderes constituídos. Se o cidadão não consegue proteção dentro das fronteiras territoriais, contemporaneamente, pode buscar a proteção de um sistema de justiça externo. A grande questão é como resgatar esta interação dentro das fronteiras do próprio Estado, que possui-a princípio - juízes conhecedores da cultura e identidade local? (MORAIS; NASCIMENTO, 2010, p. 35).

Efetivamente, o avanço do Constitucionalismo é de suma importância para o desenvolvimento estatal, especialmente em Estados denominados de "modernidade tardia", como se dá no Brasil, em que as promessas de formação de um Estado de Bem-Estar Social ainda não se concretizaram. Ao revés, nestes Estados, verifica-se um abismo entre as previsões normativas Constitucionais e a realidade social das pessoas integrantes do tecido social, principalmente, a classe menos favorecida economicamente, as quais, possuem um maior grau de dependência das ações governamentais.

Com o objetivo de aprimorar o modelo brasileiro teórico de Constitucionalismo, importante se afigura a contribuição de Silva e Brandão, ao identificar na Fraternidade importantes elementos de construção de um projeto cultural adequado. Para os autores:

A Fraternidade é o fundamento para entender a Constituição Brasileira como projeto cultural e, como categoria política, é o compasso teórico que irá restituir à Política o sentido da existência humano (existência do humano), implementando, assim, um ritmo bem brasileiro na marcha constitucional, embalando o desenvolvimento em evoluções coreografadas, de forma a não retroceder nunca nível cultural adquirido pelo Estado Constitucional brasileiro, colocado à serviço da Sociedade brasileira, criando, assim, condição para tornar a 
Sociedade critério de decisão adequada a Constituição Brasileira. (SILVA; BRANDÃO, 2015, p. 124).

O Brasil, para além das promessas constitucionais, ainda não implementou adequadamente os preceitos qualificativos do Estado de Bem-Estar Social, porquanto, ainda que tenha declarado e assumido na Constituição da República Federativa do Brasil, de 1988, inúmeros compromissos sociais, voltados para a satisfação dos anseios da Sociedade, porém o Estado brasileiro não tem conseguido cumprir os reclames nesta seara, restando evidente o hiato existente no texto constitucional com a realidade social brasileira.

Por conta deste déficit do Estado brasileiro para com as expectativas da Sociedade, frente à atuação política e jurídica voltada para a consecução das promessas encetadas na Constituição da República Federativa do Brasil de 1988 surgem, em crescimento exponencial, as demandas por ações e implementações de medidas práticas ao atendimento das necessidades da Sociedade Civil, vinculadas ao conceito de cidadania não meramente formal, mas sim uma cidadania de cunho material.

Sobre a dimensão material da cidadania, Andrade defende a ideia de que a evolução da cidadania formal para a concepção de cidadania material depende, fundamentalmente, da ocorrência de três deslocamentos:

[...] o primeiro de uma cidadania estática, cujo conteúdo está definido, para uma cidadania de conteúdo mutável, inerente ao processo histórico, mobilizado pela participação política; o segundo de uma cidadania voltada unicamente aos direitos políticos para uma cidadania mobilizadora, instituidora de direitos e deveres; e o terceiro de uma cidadania baseada na igualdade formal, no individualismo, para uma cidadania dos grupos e dos movimentos sociais (plural e coletiva) que reconhece e promove o respeito às minorias. (ANDRADE, 2003, p. 75-77).

Nesse viés, o princípio da dignidade da pessoa humana 
vem ganhando contornos cada vez mais enfáticos quanto à justificação de um direito fundamental do indivíduo voltado ao seu acesso às condições materiais e estruturais mínimas, com vistas a desfrutar de uma vida sem privações materiais básicas.

Barroso compartilha desse entendimento, ao defender que:

[...] ínsito à ideia de dignidade humana está o conceito de mínimo existencial, também chamado de mínimo social, ou o direito básico às provisões necessárias para que se viva dignamente. A igualdade em sentido material ou substantivo, e especialmente a autonomia (pública e privada) são ideias dependentes do fato de os indivíduos serem "livres de necessidades" (free from want), no sentido de que suas necessidades vitais e essenciais sejam satisfeitas. Para serem livres, iguais e capazes de exercer uma cidadania responsável, os indivíduos precisam estar além de limiares mínimos de bem-estar, sob pena de a autonomia se tornar uma mera ficção, e a verdadeira dignidade humana não existir. Isso exige o acesso a algumas prestações essenciais - como educação básica e serviços de saúde -, assim como a satisfação de algumas necessidades elementares, como alimentação, água, vestuário e abrigo. O mínimo existencial, portanto, está no núcleo essencial dos direitos sociais e econômicos, cuja existência como direitos realmente fundamentais - e não como meros privilégios dependentes do processo político - é bastante controvertido em alguns países. (BARROSO, 2014, p.84-85).

O contexto atual exige que seja suplantada a barreira hermenêutica que sustenta ser a atual Constituição da República Federativa do Brasil, apenas, uma Constituição estatutária ou orgânica, no sentido de somente pronunciar as competências estatais, além de disciplinar os processos nela contemplados, em contraponto com a ideia de Constituição dirigente.

Neste ponto, importante a lição de Grau, para quem:

[...] a Constituição do Brasil não é um mero 'instrumento de governo', enunciador de competências e regulador de processos; mas, além disso, enuncia diretrizes, fins e programas 
a serem realizados pelo Estado e pela sociedade. Não compreende somente um 'estatuto jurídico do político', mas sim um 'plano global normativo' da sociedade e, por isso mesmo, do Estado Brasileiro. (GRAU, 2015, p. 356).

A categoria Estado há de ser compreendida como a "Totalidade Social" (HELLER, 1968) e não um todo social em si, isoladamente considerado, na medida em que não há razões para se operar a distinção entre Estado e Sociedade Civil, no sentido de conferira esta, não somente a detenção de direitos subjetivos de liberdades individuais contra aquele, mas sim, conferindo a plenitude dos direitos fundamentais como expressão da soberania popular, cunhando-se, destarte, os elementos configuradores da cidadania.

Sobre o tema, importa destacar a lição de Castro e Mezzaroba, para quem:

Um Estado que é um momento da totalidade social, e não o todo social em si. O Estado não é concebido como esfera separada da sociedade civil e da família, mas como momento racional ou político do desenvolvimento dessas formas societárias. A clássica divisão liberal entre Estado e sociedade civil, sendo esta a titular de direitos públicos subjetivos "contra" aquele, não está presente na carta vigente. Ao contrário, a carta concebeu os direitos fundamentais e os direitos "públicos subjetivos" como momentos do exercício da soberania popular. (CASTRO; MEZZAROBA, 2015, p 155).

Portanto, é por este viés instrumental do Estado que há de se compreender, no âmbito do presente trabalho, a confluência dos interesses do Estado e da Sociedade Civil para que se possa implementar as garantias constitucionais inerentes à dignidade da pessoa humana e da cidadania e, com isso, propiciar, verdadeiramente, a concretização da Justiça Social, tão almejada no Brasil.

\section{PRECEDENTES JUDICIAIS}

A Sociedade brasileira contemporânea, acompanhando o cenário globalizado, vem se relacionando, cada vez mais, 
por meio de organizações de massa. Essas organizações são notabilizadas pela formação de redes de encadeamento entre grupos de indivíduos com grandes corporações comerciais, de caráter transnacional. Neste ambiente, empresas com enorme envergadura econômica praticam vultosas negociações capilares, atingindo um grande número de indivíduos, ultrapassando os limites geopolíticos delimitados pelos Estados nacionais.

Neste ambiente, não é difícil constatar o enorme potencial de litigiosidade existente, em decorrência das relações mercantis em massa, especialmente, porque as grandes corporações econômicas, em regra, buscam, primordialmente, senão exclusivamente, a maximização dos lucros, muitas vezes em detrimento do respeito aos direitos fundamentais dos cidadãos.

Em relação à vulneração de direitos fundamentais, por particulares, Sarlet adverte que:

[...] o Estado nunca foi (e cada vez menos o é) o único e maior inimigo das liberdades e dos direitos fundamentais em geral. Que tal dimensão assume particular relevância em tempos de globalização econômica, privatizações, incremento assustador dos níveis de exclusão e o aumento do poder exercido pelas grandes corporações internas e transnacionais (por vezes com faturamento e patrimônio - e, portanto, poder econômico - maior que o de muitos Estado). (SARLET, 2015, p. 91).

No contexto das relações comerciais transnacionais, diante do fenômeno da globalização, o poder regulatório dos Estados nacionais apresenta-se deveras restrito e não raras vezes, completamente inócuo, aumentado, em consequência, o cenário propício para a prática reiterada de abusos e desrespeitos contra os cidadãos.

É neste cenário que o Poder Judiciário brasileiro tem desempenhado um protagonismo crescente, desfrutando, paulatinamente, da confiança dos cidadãos, que procuram resolver seus litígios no âmbito judicial, normalmente após tentativas frus- 
tradas de composição da litigiosidade na esfera administrativa, quer por meio do insatisfatório relacionamento direto com as corporações comerciais, contratualmente a eles vinculados ( Call Center ou Central de Atendimento ao Consumidor mantido pelas empresas) quer perante a própria dificuldade de os órgãos reguladores e fiscalizadores dos Estados em darem uma resposta efetiva e com poder coercitivo em favor dos cidadãos.

A partir da implementação das ondas cappellettianas (CAPPELLETTI; GARTH, 1988) “de acesso à justiça”, passou-se a introduzir no sistema judiciário brasileiro inúmeros mecanismos voltados à superação de obstáculos ao ingresso destes indivíduos ao Poder Judiciário pátrio.

Esta nova realidade social e jurídica brasileira, ao mesmo tempo em que evidencia a crescente e salutar consciência dos cidadãos acerca da exigência perante o Poder Judiciário, de seus direitos fundamentais negligenciados pelo Estado, administrativamente, por outro lado, expõe a fragilidade do sistema judicial brasileiro, que atualmente, coloca-se diante de enormes desafios históricos, notadamente, o de possibilitar respostas adequadas, em tempo razoável e com alcance geográfico necessário ao crescente número de processos judiciais em tramitação no sistema judicial.

Para se ter ideia desta dimensão, os dados constantes do relatório denominado "Justiça em Números", referente ao ano de 2015, realizado pelo Conselho Nacional de Justiça-CNJ (BRASIL, CNJ, RELATÓRIO JUSTIÇA EM NÚMEROS, 2015), apontam que atualmente tramita no Poder Judiciário brasileiro cerca de 100 (cem) milhões de processos ativos, considerando as diversas esferas da Justiça brasileira.

Isso porque o período avaliado (2015) iniciou com um estoque de acervo com 70,8 milhões de processos e ao longo do ano ingressaram mais 28,9 milhões de novas ações judiciais, no sistema judicial brasileiro. 
Apesar de as estatísticas do Conselho Nacional de Justiça apontarem para os sucessivos recordes anuais de julgamento de processos pelos Juízes brasileiros, com aumento de 12,5\% no total de processos baixados no período compreendido entre 2009/2014, conforme o relatório mencionado, contudo, neste mesmo lapso temporal, houve um acréscimo de $17,2 \%$ de novos processos ingressados no sistema judicial brasileiro, de acordo com os dados levantados pelo CNJ.

Como se vê, o ingresso de novas demandas no sistema judicial brasileiro progride em proporções geométricas, enquanto a capacidade de produção dos magistrados brasileiros aumenta em escala aritmética.

Por outro lado, mesmo neste cenário de explosão da litigiosidade, constata-se que, ainda assim, há carência de efetivos mecanismos aptos ao rompimento de barreiras de acesso à justiça ao cidadão no Poder Judiciário brasileiro.

A radiografia apresentada aponta para uma enorme litigiosidade contida no sistema jurisdicional brasileiro, voltada para aquela espécie de demanda relacionada à lesão a direitos sofridos por litigantes eventuais, pouco familiarizados com os meandros do Poder Judiciário, comumente relacionadas aos direitos do consumidor.

A pesquisa realizada pelo Governo Federal brasileiro, por meio da Secretaria de Assuntos Estratégicos (INSTITUTO DE PESQUISA ECONÔMICA APLICADA - IPEA, 2009), revela que $64 \%$ dos cidadãos lesados subjetivamente em sua esfera jurídica não recorrem ao sistema judicial brasileiro para fazerem valer seus direitos inerentes à cidadania.

Os tradicionais mecanismos processuais civis existentes, assim como a atual estrutura do sistema judicial brasileiro não se encontram plenamente preparados para o impacto do crescente aumento de demandas, especialmente de massa. 
Por isso é que nas últimas décadas, surge um movimento no sentido de valorizar e fortalecer os pronunciamentos judiciais, na esfera do sistema processual, não só no Brasil, mas também em outros Estados nacionais. Esse movimento tem focado grandes interesses no estudo e desenvolvimento do sistema de Precedentes Judiciais

Não é o escopo de o presente trabalho investigar profundamente a teoria dos Precedentes Judiciais, em razão da limitação espacial aqui reservada, o que se fará doravante é apresentar a conceituação e alguns elementos importantes para o desenvolvimento em investigações posteriores.

Lopes Filho, embasado na proposição de círculo hermenêutico e de applicatio da filosofia de Gadamer, propõe um conceito de Precedente judicial, nos seguintes termos:

Precedente, portanto, é uma resposta institucional a um caso (justamente por ser uma decisão), dada por meio de uma applicatio, que tenha causado um ganho de sentido para as prescrições jurídicas envolvidas (legais ou constitucionais), seja mediante a obtenção de novos sentidos, seja pela escolha de um sentido específico em detrimento de outros ou ainda avançando sobre questões não aprioristicamente tratadas em textos legislativos ou constitucionais. (LOPES FILHO, 2014, p. 281-282).

Os objetivos principais na adoção de um sistema de Precedentes Judiciais são, especialmente, a agilização e a simplificação do sistema processual. Também propicia maior segurança jurídica, por meio de decisões judiciais tanto mais previsíveis quanto determinadas, em seu objeto. Além disso, dota-se de concretude o princípio da isonomia, ao ensejar que situações fáticas e juridicamente idênticas possam ter respostas judiciais semelhantes, coerentes e íntegras.

No Brasil, o Precedente Judicial começa a ter seus primeiros contornos, como sistema de aplicação no âmbito do Poder Judiciário, com o advento da Emenda Constitucional n. ${ }^{\circ} 45$, de 
30/12/2004, que alterou o texto da Constituição da República Federativa do Brasil de 1988, incluindo a previsão de súmula vinculante, sob a competência do Supremo Tribunal Federal.

Por esta alteração do texto constitucional, potencializou-se a adoção do sistema de Precedentes Judiciais em sede de controle concentrado de constitucionalidade, fazendo com que as decisões emanadas pelo Supremo Tribunal Federal, nestas espécies de demandas, passassem a produzir eficácia erga omnes.

Além disso, as decisões emanadas pelo Supremo Tribunal Federal, em sede de controle concentrado de constitucionalidade passaram a ser dotadas de efeito vinculante e obrigatório, de modo a submeter os demais órgãos integrantes do Poder Judiciário, assim como aqueles vinculados à administração pública, em todas as suas esferas e modalidades ao entendimento proclamado na decisão emanada pelo Supremo Tribunal Federal.

Nas sucessivas reformas processuais civis implementadas ao longo das últimas décadas, no Brasil, também houve progressivo disciplinamento do sistema de Precedentes, conferindo ao sistema processual mecanismos aptos ao aperfeiçoamento, possibilitando-se abreviar o tempo de tramitação do processo, ampliando os poderes de magistrados, especialmente, para alinhar a matéria em julgamento com a jurisprudência dominante dos Tribunais.

Mas foi com a edição do Novo Código de Processo Civil brasileiro, instituído pela Lei n. 13.105/2015, vigente a partir de 18 de março de 2016, que a utilização do Precedente Judicial teve alargada a sua abrangência, na busca de uma sistematização do instituto no ordenamento jurídico brasileiro.

Atualmente, no sistema processual brasileiro identificamse várias espécies de Precedentes Judiciais, os quais variam de acordo com as distintas eficácias jurídicas que produzem.

Doutrinadores apontam que "um Precedente pode ter a) efi- 
cácia vinculante ou obrigatória; b) função persuasiva; c) obstativo da revisão de decisões; d) autorizante; e) rescidente ou deseficacizante e, por fim, f) função de revisão de sentença". (DIDIER JÚNIOR; BRAGA; OLIVEIRA, 2015, p. 441).

A diminuta delimitação espacial do presente trabalho não permite detalhar as características peculiares da cada um dos Precedentes, na classificação proposta.

Entretanto, indispensável analisar o Precedente categorizado como aquele dotado de eficácia vinculante ou obrigatória.

Pois bem, o Precedente Judicial qualificado com eficácia vinculante ou obrigatória são, basicamente, aqueles constantes do art. 927 do Código de Processo Civil brasileiro de 2015, a saber: a) nas decisões do Supremo Tribunal Federal, em sede de controle concentrado de constitucionalidade; b) nos enunciados de súmula vinculante; c) nos acórdãos prolatados em incidente de assunção de competência; d) nos acórdãos prolatados em sede de resolução de demandas repetitivas; e) nos julgamentos de recursos extraordinários e especiais, sob a sistemática de repetitivos; f) nos enunciados das súmulas do Supremo Tribunal Federal, em causas relacionas a matérias constitucionais; g) nos enunciados das súmulas do Superior Tribunal de Justiça em demandas relacionadas com matéria infraconstitucional; h) nas orientações do plenário ou do órgão especial nos quais a autoridade jurisdicional estiver vinculada.

O Precedente dotado de força vinculante ou obrigatória desfruta de máxima intensidade no sistema processual, quando cotejada com as demais espécies de Precedentes, reunindo nele, também, a aptidão de produzir diversos efeitos produzidos pelas outras espécies de Precedentes, em decorrência de sua potencialidade.

Além disso, o Precedente vinculante possui traços característicos e peculiares. Primeiro, porque a força obrigatória está 
explicitada em razão de sua determinação legal. Segundo, porque em caso de inobservância, viabiliza-se a adoção do instituto processual da Reclamação, endereçada ao órgão jurisdicional prolator da decisão do qual se extraiu o Precedente obrigatório.

Já o Precedente classificado como aquele dotado, apenas, de função persuasiva, contrapõe-se, exatamente, à ideia de Precedente com força vinculativa ou obrigatória. Naquele, a existência de um determinado Precedente não possui a potencialidade de gerar a obrigação de observância nos casos similares posteriores, por nenhum órgão jurisdicional ou administrativo, ao contrário deste.

O Precedente dotado de força persuasiva possui apenas a potencialidade de nortear o julgador acerca da existência de caso semelhante, fática ou juridicamente, àquele submetido em análise posterior. Trata-se de mecanismo voltado ao convencimento das razões adotadas na decisão.

As demais classificações de Precedentes por escaparem ao escopo do presente trabalho, serão analisadas em futura investigação.

Em prosseguimento ao desenvolvimento do tema, afigurase importante a análise do que se tem reconhecido como a essência do Precedente, qual seja, a ratiodecidendi.

Outra categoria essencial para a investigação proposta e que está umbilicalmente ligada à primeira é a do termo referido como obter dictum ou no emprego em seu plural: obter dicta. Passemos, então, à análise de ambas as categorias, concomitantemente, por questão de didática.

Parte da doutrina principia a investigação do tema propondo, inicialmente que:

É possível iniciar essa distinção com uma afirmação simplória que pouco elucida a questão: ratiodecidendi é o núcleo vinculante, a parte relevante do julgamento, o qual será apli- 
cado no futuro. Já obter dictasão comentários colaterais que não obrigam os casos futuros. (LOPES FILHO, 2014, 167).

A conceituação de ratio decidendi guarda ligação umbilical com a própria categoria Precedente, tanto que para alguns investigadores o conceito deste, em sua modalidade estrita, coincide com o daquele.

Parte da doutrina defende que:

Na verdade, em sentido estrito, o Precedente pode ser definido como sendo a própria ratiodecidendi. A ratiodecidendi - ou, para os nortes americanos, a holding-são os fundamentos jurídicos que sustentam a decisão; a opção hermenêutica adotada na sentença, sem a qual a decisão não teria sido proferida como foi. "A ratiodecidendi [...] constitui a essência da tese jurídica suficiente para decidir o caso concreto (rule of law)". (TUCCI, 2004, p. 175).

E conclui:

É importante assentar o seguinte: ao decidir um caso, o magistrado cria (reconstrói), necessariamente, duas normas jurídicas. A primeira, de caráter geral, é fruto da sua interpretação/compreensão dos fatos envolvidos na causa e da sua conformação ao Direito positivo: Constituição, leis etc. A segunda, de caráter individual, constitui a sua decisão para aquela situação específica que se põe para a análise. (TUCCI, 2004, p. 175).

A existência de duas espécies de categorias geradas a partir da decisão emanada pelo órgão judicial prolator, geradora do Precedente, também é compartilhada por Buril, para quem:

Em sentido próprio, continente ou formal, é fato jurídico instrumento de criação normativa, em outras palavras: é fonte do Direito, tratando-se de uma designação relacional entre duas decisões. Já Precedente em sentido impróprio é norma, significado alcançado por redução do termo 'norma do Precedente', que é precisamente a ratiodecidendi, esse sentido é também o substancial. (BURIL, 2014, p. 92-93).

Efetivamente, a decisão judicial formadora do Precedente gera duas categorias de normas jurídicas, bastantes distintas entre si. 
A primeira norma, denominada ratiodecidendi, refere-se à enunciação firmada na tese jurídica sagrada vencedora, após os debates processuais, devidamente submetidos ao princípio do contraditório. Esta tese jurídica é caracterizada por possuir um alto grau de abstração, vale dizer, é tese dotada de generalidade, no sentido de não se considerar as minúcias que envolvem o caso concreto.

Um exemplo para ilustrar é a decisão que gerou a Súmula 227 do Superior Tribunal de Justiça. Após analisar o caso submetido a julgamento e em consideração a julgamentos de diversas situações fáticas similares, o Superior Tribunal de Justiça firmou a seguinte tese: "Pessoa Jurídica pode sofrer dano moral". Como se vê, esta formulação é oriunda da fundamentação do julgado em análise e possui evidente caráter de abstração, porquanto não indica que em todas e quaisquer circunstâncias, a pessoa jurídica sofrerá dano moral. Esta configuração dependerá da análise das circunstâncias que envolvem cada caso concreto. Porém, a ratiodecidendi encontra-se estampada na possibilidade, em tese, de que a Pessoa Jurídica, possa vir a sofrer o abalo extrapatrimonial.

Com efeito, a ratiodecidendi, é a decisão judicial que, dotada da qualidade de abstração e generalidade, extraída pelo método indutivo, por ocasião dos fundamentos da decisão, tem o condão de se desprender do caso concreto submetido a julgamento e constituir-se em norma voltada para a aplicação em outras situações concretas similares àquela que originou a edição do Precedente.

A segunda norma gerada na decisão judicial formadora do Precedente possui cunho eminentemente individual. Esta formulação possui o objetivo de dirimir o caso concreto submetido a julgamento. Refere-se à conclusão do julgado, inserido na parte dispositiva ou conclusiva da decisão.

Essa norma possui caráter individual e específico ao caso 
concreto porque delimita o encaminhamento da decisão, consistente nos direcionamentos dos pedidos formulados pelas partes ao longo do processo, "após sua submissão ao contraditório", na concepção de Fazzalari. Por ela proclama-se o conteúdo decisório do julgamento, caso em que se delibera pela procedência, improcedência ou parcial acolhimento, autorização, homologação, a depender dos pedidos formulados pelas partes no curso processual.

Outra característica importante da norma individual resultante do julgamento formador do Precedente é sua aptidão para ser acobertada pela autoridade da coisa julgada, característica que a diferencia da norma geral extraída do Precedente que não possui esta nota peculiar.

Portanto, enquanto a tese fixada como norma geral (ratiodecidendi) pode ser revista posteriormente pelo órgão prolator, como medida de superação, em atenção às técnicas do overruling e overriding ${ }^{3}$, já a norma individual extraída do julgado, por estar acobertada pela autoridade da coisa julgada possui estreitas possibilidades de revisão, em hipóteses bastantes restritas constantes do sistema processual civil brasileiro.

Superadas as considerações sobre o sistema de Precedentes, passa-se a formular, no tópico seguinte, uma tentativa de aproximação desta técnica processual com os conflitos socioambientais.

\section{CONFLITOS SOCIOAMBIENTAIS}

O modo de produção utilizado a partir da revolução industrial, por meio da expansão das plantas industriais, em escala global, inequivocamente, tem causado uma constante preocupação com a sobrevivência dos seres vivos, em todas as suas formas na terra, incluindo-se a vida humana, diante dos riscos imanentes às cíclicas catástrofes ambientais.

3 Estas técnicas de superação do Precedente refogem ao estreito âmbito do presente trabalho, razão pela qual o tema não será abordado, nesta oportunidade. 
Os riscos da modernidade atual podem ser compreendidos em diversas dimensões, sejam elas as relacionadas à nova configuração do Estado e à Sociedade ou ainda em dimensões mais contemporâneas, vinculadas às ordens ambientais ou sociais.

A proteção do meio ambiente, em suas mais diversas nuances, há de ser contextualizada com o fenômeno da sociedade de risco, edificada sobre a constatação da lógica da economia globalizada, na qual a produção social da riqueza é associada, sistematicamente, à produção de riscos.

Nesse contexto, vem-se desenvolvendo a teoria da Sociedade de Risco, expressão cunhada por Ulrich Beck, para denominar "um estágio da modernidade no qual começam a tomar corpo as ameaças produzidas até então pelo modelo econômico da sociedade industrial" (LEITE, 2007, p. 131).

Risco, para o presente contexto, é conceituado como a "[...] previsão e/ou controle (tentativas) das futuras consequências da ação humana, sobretudo, das sequelas não previstas pela modernização [...]” (FERRER; GLASENAPP; CRUZ, 2014, p. 1438)

Nesse viés, é possível categorizar a Sociedade de Risco, como "[...] aquela que, em função de seu contínuo crescimento econômico, pode sofrer a qualquer tempo as consequências de uma catástrofe ambiental [...]" (LEITE, 2007, p. 132).

Assim, é preciso considerar que os riscos ambientais não mais são considerados locais, no sentido de danos delimitados territorialmente, com extensões geograficamente determinadas. Ao contrário, os riscos ambientais apresentam-se como globais, ultrapassando barreiras territoriais, suplantando ordem transnacional e afetando, destarte, as forças mobilizadoras da política de diversos Estados.

Os efeitos dos danos ambientais na Sociedade de Risco ultrapassam a mera agressão ao ambiente ecologicamente equilibrado, para atingir, também, a forma de organização social em 
amplitude transnacional.

Para Beck:

[...] esse efeito socialmente circular de ameaça pode ser generalizado: sob a égide de dos riscos da modernização, cedo ou tarde se atinge a unidade entre culpado e vítima. No pior, no mais inconcebível dos casos - o cogumelo atômico -, isto é evidente: ele aniquila inclusive o agressor. (BECK, 2011, p. 45).

Essa conjuntura demonstra a necessidade do fortalecimento do Direito Ambiental em amplitude internacional, como mecanismo de sobrevivência entre os povos e toda a diversidade de vida existente no planeta, eis que os riscos transnacionais decorrentes das catástrofes ambientais somente serão passíveis de enfrentamento por meio de mobilização das sociedades democráticas, seja no plano nacional, quanto no internacional.

Para Beck:

O imprevisto efeito colateral da socialização da natureza é a socialização das destruições e ameaças incidentes sobre a natureza, sua transformação em contradições e conflitos econômicos, sociais e políticos: danos às condições naturais da vida convertem-se em ameaças globais para as pessoas, em termos medicinais, sociais e econômicos - com desafios inteiramente novos para as instituições sociais e políticas da altamente industrializada sociedade global. (BECK, 2011, p. 98-99).

E é aqui que se apresentam grandes transformações comportamentais na Sociedade, posto que a lógica da concentração da riqueza oriunda da sociedade industrial e, por outro lado, a distribuição dos riscos inerentes às atividades poluidoras não mais se sustenta na presente etapa civilizacional, da sociedade de risco.

Sob a perspectiva de conceber mecanismos efetivos e concretos voltados para a para a sustentabilidade é que o presente trabalho propõe uma aproximação da técnica do sistema de Precedentes com os conflitos socioambientais. 
A busca pela sustentabilidade no planeta, nas suas dimensões, sociais, econômicas e, principalmente, a ambiental tem-se constituído no grande paradigma da Sociedade atual, revelando-se a grande diretriz do Estado, no contexto da Sociedade de Risco.

Nesse sentido, Pasold destaca que:

[...] as ações de Estado e de Governo em favor do Meio Ambiente integram o conceito de Função Social, elemento essencial do Estado Constitucional Democrático de Direito, constituindo-se em dever de agir do ente público que precisa ser traduzido em agir permanentemente legitimado, eficiente, eficaz e efetivo. (PASOLD, 2013, p. 69).

Assim é que as ações e políticas do Estado em benefício da defesa do Meio Ambiente são frutos de legítimas aspirações de diversas Sociedades instituidoras de diferentes Estados.

No Brasil não é diferente, é notória a reivindicação da nossa Sociedade Civil no sentido de que o Estado Brasileiro formule políticas aptas à defesa do meio ambiente, por meio de edição de normas jurídicas voltadas para este desiderato, além da adoção de políticas e ações concretas ao fim almejado.

Essa exigência da Sociedade é que legitima o Estado a formular o espectro do dever de agir, consistentes no planejamento, tanto operacional quanto financeiro, para a implementação de ações e políticas concretas para a preservação do nosso patrimônio ambiental.

Nesse contexto e considerando o atual protagonismo do Poder Judiciário no Estado brasileiro, afigura-se plausível que o Sistema Judicial brasileira, no uso da técnica de Precedentes em matérias socioambientais, possa formular teses jurídicas constitutivas de ratiodecidendi e, portanto, editar norma geral e abstrata, com vistas à implementação de ações estatais adequadas à preservação ambiental, de modo a dar concretude à sustentabilidade. 


\section{CONCLUSÃO}

A Constituição da República Federativa do Brasil de 1988, em seu art. 225, estatui que: "Todos têm direito ao meio ambiente ecologicamente equilibrado, bem de uso comum do povo e essencial à sadia qualidade de vida, impondo-se ao Poder Público e à coletividade o dever de defendê-lo e preserválo para as presentes e futuras gerações".

Passadas quase três décadas da promulgação da Constituição brasileira, constata-se que, para além das conquistas galgadas, há muito caminho ainda para o Estado brasileiro percorrer, com vistas à implementação de efetivas políticas voltadas à sustentabilidade, nas suas dimensões ambientais, econômicas e sociais.

O Poder Judiciário tem assumido grande protagonismo na implementação de ações estatais almejadas pela Sociedade Civil em diversas áreas de atuação do Estado, que se mostram insuficiente ou deficientemente atendidas pelos cidadãos.

O desenvolvimento socioambiental da Sociedade brasileira certamente é uma das áreas mais carentes do Estado, no contexto de modernidade tardia, na qual muitas das promessas constitucionalmente preconizadas ainda aguardam efetiva concretude.

O aprofundamento das investigações acerca da utilização de um sistema de Precedentes pelo Poder Judiciário, voltado à concretização das promessas constitucionais, em especial, na seara socioambiental pode ser um caminho útil a ser trilhado, neste limiar do Século XXI.

\section{REFERÊNCIAS}

ANDRADE, Vera Regina Pereira de. Sistema penal máximo x cidadania mínima: códigos da violência na era da globalização. Porto Alegre: Livraria do Advogado, 2003.

BARROSO, Luís Roberto. A dignidade da pessoa humana no direito constitucional contemporâneo: a construção de um conceito jurídico à luz da jurisprudência mundial. Tradução de Humberto Laport de Mello. 3. reimp. Belo Horizonte: Fórum, 2014.

BECK, Ulrich. Sociedade de risco: rumo a uma outra modernidade. Tradução de Se- 
bastião Nascimento. São Paulo: Editora 34, 2011. Título original: Risikogesellschaft: auf dem weg in eineander moderne.

BRASIL. Lei n. 13.105/2015. Que institui o vigente Código de Processo Civil brasileiro. Presidência da República. Casa Civil - Subchefia para assuntos jurídicos. Brasília, DF. Disponível em:<http://www.planalto.gov.br/CCIVIL_03/_Ato2015-2018/2015/ Lei/L13105.htm. >Acesso em: 03 jul. 2016.

BRASIL. Conselho Nacional de Justiça. Justiça em números: indicadores do Poder Jurídico. 2015. Disponível em: <http://www.cnj.jus.br/programas-e-acoes/pj-justicaem-numeros.> Acesso em: 03 jul. 2016.

BRASIL. Constituição da República Federativa do Brasil de 1988. Presidência da República. Casa Civil. Subchefia para assuntos jurídicos. Brasília, DF. Disponível em: $<$ http://www.planalto.gov.br/ccivil_03/Constituicao/Constituicao.htm>. Acesso em: 03 jul. 2016.

BRASIL. Presidência da República. Secretaria de Assuntos Estratégicos. Instituto de Pesquisa Econômica Aplicada. 2009. Disponível em: $<$ http://www.ipea.gov.br/bd/ pdf/2009/Livro_BrasilDesenvEN_Vol04.pdf.> Acesso em: 03 jul. 2016.

CAPPELLETTI, Mauro; GARTH, Bryant. Acesso à justiça. Tradução de Ellen Gracie Northfleet. Porto Alegre: Sérgio Antônio Fabris, 1988. Título original: Access to Justice: The Worldwide Movement to Make Rights Effective: a general report.

CASTRO, Matheus Felipe de; MEZZAROBA, Orides. História ideológica e econômica das constituições brasileiras. Belo Horizonte: Arraes, 2015.

DIDIER JUNIOR, Fredie; BRAGA, Paulo Sarna; OLIVEIRA, Rafael Alexandria de. Curso de direito processual civil. Volume 2. 10. ed. rev. ampl. e atual. Salvador: Jus Podivm, 2015.

FAZZALARI, Elio. Instituições de direito processual. Campinas: Bookseller, 2006. Título original: Instituzioni di diritto processuale.

FERRER, Gabriel Real; GLASENAPP, Maikon Cristiano; CRUZ, Paulo Márcio. Sustentabilidade: um novo paradigma para o direito. Revista Novos Estudos Jurídicos Eletrônica, Vol. 19, n. 4 - Edição Especial, 2014.

GRAU, Eros Roberto. A ordem econômica na Constituição de 1988. 17. ed. rev. atual. São Paulo: Malheiros, 2015.

HELLER, Hermann. Teoria do estado. Tradução de Lycurgo Gomes da Motta. São Paulo: Mestre Jou,1968. Título original: Staatslehre.

LEITE, José Rubens Morato. Sociedade de Risco e Estado. In: CANOTILHO, Joaquim Gomes. LEITE, José Rubens Morato (Orgs.). Direito constitucional ambiental brasileiro. São Paulo: Saraiva, 2007.

LOPES FILHO, Juraci Mourão. Os precedentes judiciais no constitucionalismo Brasileiro. Salvador: Jus Podivm, 2014.

MACÊDO, Lucas Buril. Precedentes judiciais e o direito processual civil. Salvador: Jus Podivm, 2014.

MORAIS, José Luiz Bolzan de; NASCIMENTO, Valéria Ribas de Morais. Constitucionalismo e cidadania: por uma jurisdição constitucional democrática. Porto Alegre: 
Livraria do Advogado, 2010.

PASOLD, Cesar Luiz. Função social do estado contemporâneo. 4. ed. rev. amp. Itajaí/ SC: Univali, 2013. Disponível em: <ebookhttp://siaiapp28.univali.br/LstFree.aspx.>. Acesso em: 30 maio 2017.

PASOLD, Cesar Luiz. Metodologia da pesquisa jurídica: teoria e prática. 13. ed. rev. atual. ampl. Florianópolis: Conceito Editorial, 2015.

SARLET, Ingo Wolfgang. Dignidade (da pessoa) humana e direitos fundamentais na Constituição Federal de 1988. 10. ed. rev. atual. ampl. Porto Alegre: Livraria do Advogado, 2015.

SILVA, Celso de Albuquerque. Do efeito vinculante: sua legitimação e aplicação. Rio de Janeiro: Lumen Juris, 2005.

SILVA, Ildete Regina Vale da Silva e BRANDÃO, Paulo de Tarso. Constituição e fraternidade: o valor normativo do preâmbulo da constituição. Curitiba: Juruá, 2015.

TUCCI. José Rogério Cruz e. Precedente judicial como fonte do direito. São Paulo: RT. 2004.

Artigo recebido em: 14/03/2017

Artigo aprovado em: 02/10/2017 